\title{
Functional outcome of patients treated with proximal humeral internal locking osteosynthesis plate in proximal humeral fractures
}

\author{
Tigy Thomas Jacob, Manmatha Nayak*
}

Department of Orthopaedics, Government Medical College, Kottayam, Kerala, India

Received: 03 July 2020

Accepted: 04 August 2020

\section{*Correspondence:}

Dr. Manmatha Nayak,

E-mail: manmatha0002@gmail.com

Copyright: ( $)$ the author(s), publisher and licensee Medip Academy. This is an open-access article distributed under the terms of the Creative Commons Attribution Non-Commercial License, which permits unrestricted non-commercial use, distribution, and reproduction in any medium, provided the original work is properly cited.

\begin{abstract}
Background: Displaced or unstable proximal humeral fractures fare poorly with non-operative treatment. These are better treated with surgical intervention in order to prevent minimal displacement of tuberosity or articular surface from compromising the long term articular function. The objective was to assess the functional outcome of patients treated with PHILOS (the proximal humeral internal locking osteosynthesis) plate in proximal humerus fracture.

Methods: 42 patients age group range between 20 and 80 years $61.9 \%$ are male and $38.1 \%$ are female treated with philos plate. Functional outcome measured by using Constant and Murley score.

Results: 50\% were Neer two part fractures, 35.7\%, three part fractures, 14.3\%, four part fractures. After 6 month follow up functional outcome assessed by using constant and Murley score. Excellent outcome in 1 (2.4\%) good outcome in $13(31 \%)$, fair outcome in $19(45.2 \%)$ and poor outcome in $9(21.4 \%)$ noted.

Conclusions: PHILOS plate fixation of proximal humerus fracture is an effective surgical technique in maintaining stability of fractures and there is significant improvement in functional outcome.
\end{abstract}

Keywords: Proximal humerus fracture, PHILOS plate, Constant and Murley score

\section{INTRODUCTION}

Proximal humeral fractures are now recognized as an increasingly common fracture accounting for $4 \%$ to $5 \%$ of all fractures and $45 \%$ of all humeral fractures. ${ }^{1,2}$ It is the third most common fracture, in people above 65 years of age, after fractures of the hip and distal radius. ${ }^{3}$ These fractures have a bimodal distribution occurring either in young people following high energy trauma or in those older than 50 years with low velocity injuries like simple fall.3 $85 \%$ of these fractures are minimally displaced and are effectively treated with immobilization followed by early motion. The remaining $15 \%$ of these are either displaced or unstable. ${ }^{4}$ These fares poorly with nonoperative treatment and are better treated with surgical intervention. Surgical treatment is necessary especially in young patients and active elderly people in order to prevent minimal dislocations of tuberosity or articular surface from compromising the long-term articular function.
The aim of treatment in proximal humeral fractures is to achieve a painless and simultaneously functional shoulder. This result depends on the age, medical condition, bone quality and expectations of the patient as well as a good evaluation of the current fixation techniques. Traditional treatment techniques include open reduction and internal fixation with proximal humeral plates, hemiarthroplasty, and percutaneous or minimally invasive techniques such as pinning, screw osteosynthesis, and the use of intramedullary nails. Loosening or failure of the implant and nonunion are possible complications of surgery in humeral fractures. There is still no treatment that can be the golden standard in this fractures. ${ }^{5-8}$

In order to decrease the high complication rates of proximal humeral fractures, the AO/ASIF group developed the PHILOS (the proximal humeral internal locking osteosynthesis) plate (Synthes, Stratec Medical ltd, Mezzovico, Switzerland); an internal fixation system 
that enables angled stabilization with multiple interlocking screws. However, there are few prospective studies available that actually evaluate the results of this technique or report on the treatment-related complications. ${ }^{9-17}$ This study was planned to evaluate the outcome of proximal humerus fractures managed with PHILOS plate after approval by the institutional ethical board. The objective of the study was to assess the functional outcome of patients treated with PHILOS plate in proximal humeral fractures.

\section{METHODS}

\section{Study design}

This study was prospective, observational study period of November 2017 to June 2018.

\section{Study population}

Patients with proximal humerus fracture treated with PHILOS plate in Department of Orthopaedics, Government Medical College, Kottayam during the study period.

\section{Sample size}

According to study by Kumar et al, on functional outcome of proximal humerus fracture treated with PHILOS plate excellent/good result was found to be $70.96 \% .^{18}$

$$
\begin{aligned}
& \text { Sample size, } n=4 p q / d^{2} \\
& \qquad \begin{aligned}
p \rightarrow 70.96 q & =100-p=29.04, d=20 \% \text { of } p \\
& =20 \% \text { of } 70.96 \\
& =14.19
\end{aligned} \\
& \text { So } n=(4 \times 70.96 \times 29.04) /(14.19 \times 14.19) \\
& =40.93=41
\end{aligned}
$$

\section{Inclusion criteria}

All patients presenting with proximal humeral fractures according to Neer two, three and four fracture age range 20 to 80 years, patients with associated dislocation of shoulder were included.

\section{Exclusion criteria}

Pathologic fractures from primary or metastatic tumors, patients age less than 20 years and greater than 80 years and open fractures were excluded.

\section{Statistical analysis}

Data was entered in Microsoft Excel software, and analysis was done using Statistical Package for the Social Sciences (SPSS) version 20.0 software. The level of

significance will be $\mathrm{p}$ value $<0.05$ and high significance $\mathrm{p}$ value $<0.01$. The data is collected using the proforma. The results are analyzed at the end of the study and observations made.

\section{Study procedure}

After obtaining approval for the study from institutional review board, written informed consent from patients Information was collected through prepared proforma from each patient. All patients were interviewed as per the prepared proforma and then complete clinical examination was done. Cases history, physical findings, investigation results, treatment details was entered in the proforma by the investigator. The data collected was analyzed using appropriate statistical software.

\section{RESULTS}

\section{Neer type of fracture}

In this study population 21 patients $(50 \%)$ were two part fracture 15 patients $(35.7 \%)$ were three part fracture, 6 patients $(14.3 \%)$ were four part fracture (Table 1$)$.

Table 1: Distribution of study population based on Neer type of fracture.

\begin{tabular}{|lll|}
\hline Type of fracture & Frequency & Percentage \\
\hline Two part fracture & 21 & 50 \\
\hline Three part fracture & 15 & 35.7 \\
\hline Four part fracture & 6 & 14.3 \\
\hline Total & 42 & 100 \\
\hline
\end{tabular}

\section{Radiological fracture union}

In this study population 7 patients $(16.7 \%)$ fracture united in 6 weeks, 12 patients $(28.6 \%)$ fracture united in 8 weeks, 7 patients $(16.7 \%)$ fracture united in 10 weeks, 5 patients (11.9\%) fracture united in 12 weeks, 3 patients $(7.1 \%)$ fracture united in 14 weeks, 4 patients $(9.5 \%)$ fracture united in 16 weeks and 4 patients $(9.5 \%)$ fracture united in 18 weeks. 10.62 weeks mean union of fracture with standard deviation of 3.863 (Table 2).

Table 2: Distribution of study population based on fracture union.

\begin{tabular}{|lll|}
\hline $\begin{array}{l}\text { Fracture union in } \\
\text { weeks }\end{array}$ & Frequency & Percentage \\
\hline $\mathbf{6}$ & 7 & 16.7 \\
\hline $\mathbf{8}$ & 12 & 28.6 \\
\hline $\mathbf{1 0}$ & 7 & 16.7 \\
\hline $\mathbf{1 2}$ & 5 & 11.9 \\
\hline $\mathbf{1 4}$ & 3 & 7.1 \\
\hline $\mathbf{1 6}$ & 4 & 9.5 \\
\hline $\mathbf{1 8}$ & 4 & 9.5 \\
\hline Total & 42 & 100 \\
\hline
\end{tabular}




\section{Complications}

In this study population 8 patients (19\%) had complication and 34 patients $(81 \%)$ had no complication (Table 3 ).

\section{Table 3: Distribution of study population based on} complications.

\begin{tabular}{|lll|}
\hline Complication & Frequency & Percentage \\
\hline No & 34 & 81 \\
\hline Yes & 8 & 19 \\
\hline Total & 42 & 100 \\
\hline
\end{tabular}

\section{DISCUSSION}

Open reduction and internal fixation (ORIF) provides the features of anatomical fracture reduction, rigid fixation and the possibility of bone grafting. In proximal humerus fractures, PHILOS plate offers good functional outcome with context to the early joint mobilization and rigid fixation of the fracture. The present study was undertaken to assess the functional outcome of patients treated with PHILOS plate in proximal humerus fracture.

The present prospective study was conducted from November 2017 to June 2018. A total of 42 patients who sustained proximal humerus fracture were enrolled. Patients underwent open reduction and internal fixation using PHILOS plate through deltopectoral approach. In this study, patients with only 2-part, 3-part and 4-part fracture of proximal humerus were included based on Neer's classification. Accordingly, the 2-part fractures were noted in most of the cases $(50 \%)$ followed by 3-part $(35.7 \%)$ and 4-part (14.3\%).

Kristiansen and Christensen have reported a high incidence of fixation failure following use of T-buttress plates in fixation of proximal humerus fractures. ${ }^{19}$ Recently newer implants such as the Plan Tan humerus fixator plate, Polaris nail and the PHILOS plate have been used for fixation of proximal humerus fractures. The plate is pre-shaped and contoured for the proximal humerus. The benefits of this implant are that it gives enhanced purchase in osteopenic bone, there is no loss of reduction or varus/valgus angulations, the locking screws into the plate provide angular and axial stability of the construct. With regard to functional outcome following use of locking plates (PHILOS) early benefits can be gained. The other demanding aspect is to avoid placing the plate too proximally on the humerus with resulting impingement of the top of the plate on the acromion. This can be avoided by using a $\mathrm{K}$ wire inserted through a hole at the top of the plate, which should line up with the tip of the greater tuberosity. This is done during initial positioning of the plate. Positioning the plate too high can also lead to incorrect placement of the divergent screws in the humeral head. In the present study open reduction and internal fixation through deltopectoral approach with PHILOS plate was carried out and excellent $1(2.4 \%)$, good 13 (31\%), fair $19(45.2 \%)$ outcome and 9 (21.4\%) poor outcome noted. No statistically significant association was noted between type of fracture and outcome, there was association between age group and constant score outcome. Fracture union occurred between 6 weeks to 18 weeks. Mean of 10.62 weeks and standard deviation of 3.863. The range of motion at first, second and third follow ups showed gradual increase in mean flexion, abduction, external rotation and internal rotation during subsequent follow ups. These findings suggest that internal fixation with PHILOS (proximal humeral internal locking system) plate for proximal humerus fractures results in overall good results that is nearly $78.6 \%$ of the patients had excellent good and fair results.

Esser et al reported excellent results in 22 out of his 26 patients of three part and four part fractures of proximal humerus treated with a modified clover leaf plate. ${ }^{20}$ Paavolainen et al reported satisfactory results in $74.2 \%$ of their 41 patients with severe proximal humerus fractures treated with plate and screw devices. ${ }^{21}$ In a study Koukakis et al prospectively evaluated 20 patients with fractures of the proximal humerus. ${ }^{10}$ According to their experience, the plate design provides stable fixation with a good functional outcome and eliminates most hardware problems such as failure and impingement. In 2009 Fazal et al retrospectively reviewed 27 patients who underwent locking compression plate fixation. ${ }^{22}$ The constant shoulder score was $>75$ in 11 patients, 13 were scored between 50 to 75 , and 3 below 50. They concluded PHILOS plate fixation provided stable fixation, minimal metal work problem and enabled early range of motion exercises to achieve acceptable functional. In 2009, Brunner et al in his multicenter study from 8 trauma units enrolled 157 patients and treated with open reduction and internal fixation with a PHILOS plate. ${ }^{23}$ The incidence of experiencing any implant-related complication was $9 \%$ and $35 \%$ for non-implant related complications. Primary screw perforation was the most frequent problem (14\%) followed by secondary screw perforation (8\%) and avascular necrosis $(8 \%)$. After 1 year, a mean constant score of 72 points $(87 \%$ of the contralateral non-injured side), a mean Neer's score of 76 points, and mean disabilities of the arm, shoulder, and hand score of 16 points were achieved. They concluded that fixation with philos plates preserves achieved reduction, and a good functional outcome can be expected. Proximal humerus fractures, remain a challenging problem for the surgeon because the complication rate for these fractures still remains high. The internal locked system (PHILOS) plate is a new device used for proximal humerus fracture fixation is designed to decrease the high complication rate. In the present study complications observed were $8 \%$.

\section{CONCLUSION}

PHILOS plate is a locking plate. This provides a high degree of angular and axial stability eliminating screw loosening and back out. The divergent and convergent orientation of the screws engaging in the humeral head prevent pull out and failure of fixation. 
PHILOS plate was found to be stable fixation for all Neers 2 part, 3 part and 4 part fracture subsequently help in early mobilization and better functional outcome.

Funding: No funding sources

Conflict of interest: None declared

Ethical approval: The study was approved by the institutional ethics committee

\section{REFERENCES}

1. Palvanen M, Kannus P, Niemi S, Parkkari J. Update in the epidemiology of proximal humeral fractures. Clin Orthop Relat Res. 2006;442:87-92.

2. Spence RJ. Fractures of the proximal humerus. Curr Opin Orthop. 2003;14:269-80.

3. Baron JA, Barrett JA, Karagas MR. The epidemiology of peripheral fractures. Bone. 1996;18(3):209-13.

4. Court-Brown CM, Garg A, McQueen MM. The epidemiology of proximal humeral fractures. Acta Orthop Scand. 2001;72:365-71.

5. Robinson CM, Page RS. Severely impacted valgus proximal humeral fractures: Results of operative treatment. J Bone Joint Surg Am. 2003;85:1647-55.

6. Wanner GA, Wanner-Schmid E, Romero J, Hersche $\mathrm{O}$, von Smekal A, Trentz O, Ertel W. Internal fixation of displaced proximal humeral fractures with two one-third tubular plates. J Trauma. 2003;54:536-44.

7. Park MC, Murthi AM, Roth NS, Blaine TA, Levine WN, Bigliani LU. Two-part and three-part fractures of the proximal humerus treated with suture fixation. J Orthop Trauma. 2003; 17:319-25.

8. Schmal H, Klemt C, Sudkamp NP. Evaluation of shoulder arthroplasty in treatment of four-fragment fractures of the proximal humerus. Unfallchirurg German. 2004;107:575-82.

9. Fankhauser F, Boldin C, Schippinger G, Haunschmid C, Syzszkowitz R. A new locking plate for unstable fractures of the proximal humerus. Clin Orthop Relat Res. 2005;430:176-81.

10. Koukakis A, Apostolou CD, Taneja T, Korres DS, Amini A. Fixation of proximal humerus fractures using the PHILOS plate: early experience. Clin Orthop Relat Res. 2006;442:115-20.

11. Kettler M, Biberthaler P, Braunstein V, Zeiler C, Kroetz M, Mutschler W. Treatment of proximal humeral fractures with the PHILOS angular stable plate. Presentation of 225 cases of dislocated fractures. Unfallchirurg German. 2006;109:1032-40.

12. Sudkamp N, Bayer J, Hepp P, Voiqt C, Oestern H, Kabb M, Luo C, Plecko M, Wendt K, Kostler W, Konrad G. Open reduction and internal fixation of proximal humeral fractures with use of the locking proximal humerus plate. Results of a prospective, multicenter, observational study. J Bone Joint Surg Am. 2009;91(6):1320-8.

13. Aggarwal S, Bali K, Dhillon MS, Kumar V, Mootha AK. Displaced proximal humeral fractures: an Indian experience with locking plates. J Orthop Surg Res. 2010;5:60.

14. Bigorre N, Talha A, Cronier P, Hubert L, Toulemonde JL, Massin P. A prospective study of a new locking plate for proximal humeral fracture. Injury. 2009;40(2):192-6.

15. Yang H, Li Z, Zhou F, Wang D, Zhong B. A prospective clinical study of proximal humerus fractures treated with a locking proximal humerus plate. J Orthop Trauma. 2011;25:11-7.

16. Helwig P, Bahrs C, Epple B, Oehm J, Eingartner C, Weise K. Does fixed-angle plate osteosynthesis solve the problems of a fractured proximal humerus?. A prospective series of 87 patients. Acta Orthop. 2009;80:92-6.

17. Shahid R, Mushtaq A, Northover J, Maqsood M. Outcome of proximal humerus fractures treated by PHILOS plate internal fixation. Experience of a district general hospital. Acta Orthop Belg. 2008;74:602-8.

18. Satpathy GK, Chand DK. Functional outcome of proximal humerus fracture treated with philos plate. Int J Orthop Sc. 2017;3(2):169-72.

19. Kristiansen B, Christensen SW. Plate fixation of proximal humeral fractures. Acta Orthop Scand. 1986;57:320-3.

20. Esser RD. Treatment of three and four part fractures of the proximal humerus with a modified cloverleaf plate. J Orthop Trauma. 1994;788-91.

21. Paavolainen P, Bjorkenheim JM, Slatis P, Paukku P. Operative treatment of severe proximal humeral fractures. Acta Orthop Scand. 1983;54:374-9.

22. Fazal MA, Haddad FS. Philos plate fixation for displaced proximal humeral fractures. J Orthop Surg (Hong Kong). 2009;17(1):15-8.

23. Brunner F, Sommer C, Bahrs C, Heuwinkel R, Hafner C, Rillmann $\mathrm{P}$, et al. Open reduction and internal fixation of proximal humerus fractures using a proximal humeral locked plate: a prospective multicenter analysis. J Orthop Trauma. 2009;23:16372.

Cite this article as: Jacob TT, Nayak M. Functional outcome of patients treated with proximal humeral internal locking osteosynthesis plate in proximal humeral fractures. Int J Res Orthop 2020;6:1182-5. 